\title{
A revolução cubana e as representações sociais de gênero
}

Giselle Cristina dos Anjos Santos*

\section{Resumo:}

Este artigo possui como objetivo discutir as representações sociais de gênero atribuídas a mulheres e homens no processo da revolução cubana, entre 1959 e 1980 . A superação das desigualdades sociais de gênero foi definida como uma das prioridades do governo revolucionário na construção do projeto político socialista. A partir da análise de fontes oficiais produzidas pelo Estado, debatemos as rupturas e permanências nas representações dos códigos de gênero, evidenciadas pela existência de ambiguidades e contradições existentes entre o discurso e a prática política do governo e suas instituições. As leituras sobre o homem novo, o guerrilheiro revolucionário, a homossexualidade, as funções sociais da maternidade, a moral sexual e a representatividade nos espaços de poder, estiveram entremeadas com representações de códigos hierárquicos já existentes na sociedade cubana desde o contexto anterior à revolução.

Palavras-chaves: Cuba; revolução; representações de gênero.

\begin{abstract}
:
This article has as objective to discuss the social representations of gender assigned to women and men in the process of the Cuban Revolution, between 1959 and 1980. Overcoming social inequalities of gender was defined as one of the priorities of the revolutionary government in the construction of socialist political project. From the analysis produced by the state officials, discussing the ruptures and continuities in the representation of gender codes, as evidenced by the existence of ambiguities and contradictions between discourse and political practice of the government and its institutions. The readings on the new man, the revolutionary guerrilla, homosexuality, the social functions of motherhood, sexual morality and representation in positions of power, were interspersed in representations of hierarchical codes existing in Cuban society from the context that preceded the revolution.
\end{abstract}

Key words: Cuba; revolution; representations of gender.

\section{Introdução}

\footnotetext{
Mestranda em Estudos Interdisciplinares sobre Mulheres, Gênero e Feminismo da Universidade Federal da Bahia. E-mail: giselle.santos@afrika.org.br
}

Revista Eletrônica da ANPHLAC, n.14, p. 265-286, jan./jun. 2013.

http://revista.anphlac.org.br/index.php/revista 
Este artigo possui como objetivo refletir sobre as relações de gênero no contexto de transformações sociais da revolução cubana, que constitui um marco na História recente da América Latina, a partir das categorias analíticas de gênero e representações sociais.

A revolução cubana (1959) inspirou partidos políticos e movimentos sociais na construção de projetos políticos de emancipação na segunda metade do século XX. A sociedade cubana passou a constituir o imaginário sociopolítico latino-americano como sinônimo da emancipação desejada, pois enquanto o continente estava sob o jugo das ditaduras militares, Cuba era um território "livre".

Nas últimas décadas produziu-se uma vasta bibliografia sobre a referida revolução em inúmeros países a partir de diversas áreas de conhecimento, na que foram enfatizados aspectos diferenciados ${ }^{1}$. No Brasil muitos intelectuais, ligados a tendências políticas distintas, produziram reflexões sobre a revolução cubana ${ }^{2}$. Mas, apesar da vasta produção bibliográfica, a experiência das mulheres e a temática de gênero foram pouco problematizadas no contexto brasileiro ${ }^{3}$.

A invisibilidade das mulheres nas análises sobre a revolução cubana corrobora o silenciamento que permeou a experiência das mulheres na produção do conhecimento, de maneira geral, e da produção historiográfica, em particular Segundo a historiadora

\footnotetext{
1 No que tange o debate bibliográfico, a produção sobre a revolução cubana é muito extensa, dentro e fora do país. Contudo, posicionamentos visivelmente tendenciosos, de extremadas críticas ou exaltações ao processo político foram comuns, principalmente durante o período da Guerra Fria. Mas, ainda é possível observar tais perspectivas em trabalhos recentes.

Alguns trabalhos sobre Cuba publicados por pesquisadores brasileiros, de diferentes áreas de conhecimento, entre as décadas de 1960 e 1980: BAMBIRRA, Vânia. Cuba: 20 anos de cultura. São Paulo: Hucitec, 1983; BRANDÃO, Ignácio de Loyola. Cuba de Fidel. Viagem à ilha proibida. São Paulo: Livraria Cultura Editora, 1978; DUTRA, Hélio. Querida Ilha. São Paulo: Edições Mandacaru, 1988; ESCOSTEGUY, Jorge. Cuba hoje: 20 anos de Revolução. São Paulo: Alfa-Omega, 1978; FERNANDES, Florestan. Da guerrilha ao socialismo: a Revolução Cubana. São Paulo: T.A.Q. ed., 1979; MATOS, Almir. Cuba: A Revolução na América. Rio de Janeiro: Ed. Vitória, 1961; MORAES, Fernando. A Ilha. Um repórter no país de Fidel Castro. São Paulo: Ed. Alfa-Omega, 1985, 22ª edição; QUINTANEIRO, Tânia. Cuba e Brasil: da Revolução ao Golpe (1959-1964). Uma interpretação sobre a política externa independente. Belo Horizonte: Editora da UFMG, 1988; SADER, Emir. A Revolução Cubana. São Paulo: Moderna, 1985; ZAGURI, Tania. A Escola em Cuba. São Paulo: Brasiliense, 1988.

3 De nosso conhecimento, pesquisas publicadas no Brasil sobre a revolução cubana e as relações de gênero, são as seguintes: CABRERA, Olga. CARRIJO, Orlinda Melo. Brasil e Cuba: Sociedade, história na interseção do gênero, raça e classe social. Revista Brasileira do Caribe, vol. XI, nº 21-jul/dez. 2010, p.79-102. CÉSAR, Maria Auxiliadora. Mulher e Política Social em Cuba: o contraponto socialista ao bem-estar capitalista. Brasília: Alva, 2005. POEY, Dionisio Lazáro Baró. Cuba: Estratégias de sobrevivência de mulheres negras (século XX). $210 \mathrm{f}$. (Tese de Doutorado) Instituto de Ciências Humanas - Departamento de História - Universidade de Brasília, 2009. VASSI, Cassia. A família cubana segundo o Código de 1975: novos homens, mulheres e crianças. Trabalho de Conclusão do Curso de História. Faculdade de História, Direito e Serviço Social - Universidade Estadual Paulista/Franca, 2003. VASSI, Cassia. Mulheres em Cuba. Uma perspectiva jurídica (1901-1976). 102f (Dissertação de Mestrado) Faculdade de História, Direito e Serviço Social - Universidade Estadual Paulista, Franca, 2006.
}

Revista Eletrônica da ANPHLAC, n.14, p. 265-286, jan./jun. 2013. http://revista.anphlac.org.br/index.php/revista 
pós-estruturalista Joan Scott, "La historia del desarrollo de la sociedad humana ha sido narrada casi siempre por hombres, y la identificación de los hombres con la 'humanidad' ha dado por resultado, casi siempre, la desaparición de las mujeres de los registros del pasado." (SCOTT, 1992, p. 39).

Acreditamos que a compreensão de como as mulheres cubanas passaram a compor as diferentes esferas sociais, às quais anteriormente a 1959 não tinham acesso, se encontra para além da análise de dados e números estatísticos. Neste sentido, interessa-nos relacionar a construção discursiva do social e a construção social dos discursos para refletir acerca de que maneira foi proposta a integração social das mulheres, ao analisar quais foram às representações de gênero presentes no discurso do Estado socialista cubano entre 1959 e 1980.

Para desenvolver tal reflexão, analisamos discursos políticos de Fidel Castro, as resoluções dos três primeiros congressos da Federación de Mujeres Cubanas ${ }^{4}$, o Código de Família (1975) e as Resoluções do Primeiro Congresso Nacional de Educação e Cultura de Cuba (1971). Ou seja, fontes oficiais, produzidas pelo Estado socialista com a finalidade de instituir novas práticas e representações sociais para a atribuição de um novo sentido as relações sociais. Pois, como afirma a historiadora Sandra Pesavento "O discurso e a imagem, mais do que meros reflexos estáticos da realidade social, podem vir a ser instrumentos de constituição de poder e transformação da realidade" (1995, p. $18)$.

Como referência para a interpretação de nossas fontes, adotamos a categoria analítica de gênero, elaborada por Scott (1995) e a categoria de representações sociais, formulada pelo historiador Roger Chartier (1998).

Scott compreende a categoria de gênero como um elemento constitutivo das relações sociais baseadas nas diferenças que distinguem os sexos, instituindo-se como uma forma primária das relações significantes de poder. Para a autora, gênero implica quatro dimensões constitutivas: 1- símbolos culturalmente disponíveis que evocam representações simbólicas (e com freqüência contraditórios); 2- conceitos normativos que expõem interpretações de significados dos símbolos; 3- a noção de fixidez que leva a aparência de uma permanência atemporal na representação binária do gênero; e 4- a

\footnotetext{
4 Analisamos as resoluções dos três primeiros congressos da Federacion de Mujeres Cubanas que ocorreram respectivamente em 1962, 1974 e 1980 (ESPÍN, 1990).
}

Revista Eletrônica da ANPHLAC, n.14, p. 265-286, jan./jun. 2013. http://revista.anphlac.org.br/index.php/revista 
noção restritiva de identidade subjetiva. Apesar de não operarem simultaneamente, nenhum desses quatro elementos pode operar sem os outros (SCOTT, 1995, pp. 86-87).

Chartier entende as representações sociais como figuras graças às quais o presente pode adquirir sentido, ao permitir ver uma coisa ausente. As representações do mundo social são construídas através de disputas de poder e de dominação que almejam organizar a universalidade de um diagnóstico fundado na razão, mas são sempre formulados de acordo com os interesses do grupo que as forjam. Para Chartier, a categoria de representações sociais permite articular três modalidades da relação com o mundo social: 1- o trabalho de classificar e delimitar, produzindo configurações intelectuais, através das quais a realidade é contraditoriamente constituída pelos diferentes grupos; 2- as práticas sociais visam reconhecer uma identidade social, exibir uma forma especifica de estar no mundo, definir simbolicamente um estatuto e uma posição; e 3- as formas institucionalizadas e objetivadas sob as quais uns "representantes" (instâncias coletivas ou pessoas singulares) definem de forma explicita e perpetuadas à existência do grupo, da classe ou da comunidade (CHARTIER, 1988, p. 23).

Acreditamos que a articulação das categorias de representações sociais, segundo Chartier, e a categoria de gênero, a partir das definições de Scott, oferecem mecanismos para interpretar quais foram às transformações que ocorreram nas representações sociais de gênero e nas dimensões simbólicas de poder com as mudanças na organização das relações sociais em Cuba, no contexto da revolução socialista entre 1959 a 1980.

\section{Antecedentes históricos}

A constituição de Cuba no século XVI, como colônia espanhola, representou a formação de uma sociedade de estrutura hierárquica fundamentada em valores de classe, raça e gênero que subordinava mulheres, negros e pobres. Para a construção e manutenção da estrutura das sociedades coloniais foi essencial para as elites o controle da sexualidade e capacidade procriadora das mulheres, através de sistemas de valores sexistas e racistas.

A representação do poder bélico/militar nas guerras, batalhas e revoluções, importantes elementos da história e da identidade da sociedade cubana, erigiu padrões de comportamento de gênero para os homens cubanos fundamentados em noções de virilidade, marginalizando os que não se encaixavam nestes referenciais hegemônicos.

Revista Eletrônica da ANPHLAC, n.14, p. 265-286, jan./jun. 2013. http://revista.anphlac.org.br/index.php/revista 
É notável a defesa de um padrão de comportamento de gênero fixamente dicotômico na "Carta crítica del hombre muger" publicada em 10 de abril de 1791 no jornal Papel Periódico de La Habana, no qual o autor, que assina com o pseudônimo El Amante del Periódico, traça críticas aos homens que não seguem o perfil hegemônico,

Por puntos se aumenta el número de los que quieren hacerse Mugeres en sus trages y acciones con notable detrimento del estado y con gran dolor de los hombres de juicio [...]. ¿Si se ofreciera defender á la Patria, qué tendríamos que esperar en semejantes Ciudadanos o Narcisillos? ¿Podría decirse que estos tienen aliento para tolerar las intemperies de la Guerra? ¿Cómo han de ser varones fuertes y esforzados, los que así ostentan su ánimo mujeril y apocado? Desengañémonos, el que se cría con músicas, bayles, regalos e deleites, forzosamente genera en femeniles costumbres (VITIER; GARCÍA; FRIOL, 1990, pp. 76-77 apud SIERRA, 2006, p. 26)

O autor estabeleceu críticas aos homens que assumiam papéis sociais construídos historicamente como femininos, lhes imputando o título de "hombre muger". E questiona a capacidade destes homens de defenderem a pátria e atuarem na guerra. Segundo a concepção presente na carta, somente homens fortes e viris, mas, sobretudo com orientação heterossexual, poderiam desempenhar o papel de defesa da pátria. Neste período, a pederastia ou sodomia ${ }^{5}$ eram práticas penalizadas, classificadas como crimes contra a honestidade.

Assim como os outros processos de independência latino-americanos, o processo de independência de Cuba frente à Espanha foi bastante complexo. Houve três guerras contra o poderio espanhol durante o século XIX, a Guerra dos Dez Anos entre 18681878, a Guerra Chiquita de 1879-1880 e o terceiro conflito de $1895-1898^{6}$. Foi atribuído aos homens o exercício do poder bélico/militar, no cumprimento do dever de lutar nas guerras pela independência política de Cuba. As representações sobre a masculinidade dos mambises $^{7}$ foram constituídas através de referenciais de força e virilidade,

\footnotetext{
5 As relações erótico-afetivas entre pessoas do mesmo sexo foram denominadas de pederastia ou sodomia até o final do século XIX. E, segundo Sierra (2006, p. 28), se a pederastia ou sodomia masculina constituía motivos para escândalos na sociedade cubana no período colonial, as relações entre mulheres chocavam mais intensamente.

6 Na terceira guerra de independência entre Cuba e Espanha (1895-1898) houve a interferência do governo dos Estados Unidos. Com a distância geográfica de apenas 90 milhas, o país norte-americano agiu de maneira estratégica ao intervir na guerra. Com a derrota do país europeu, o governo norteamericano assinou um acordo que garantia a administração política de Cuba e a ilha passou a ser seu protetorado. Tal condição permaneceu de 1898 até 1902, quando se funda a República de Cuba, porém a interferência política do governo norte-americano na ilha ocorreu até a revolução de 1959.

7 Mambises foi o termo empregado para designar os integrantes do exército libertador de Cuba no século XIX. O exército foi composto por cubanos de diferentes classes sociais e origens étnico-raciais, houve até mesmo estrangeiros, no entanto, a maioria dos combatentes eram homens negros e mulatos, na condição de escravizados e libertos.
}

Revista Eletrônica da ANPHLAC, n.14, p. 265-286, jan./jun. 2013. http://revista.anphlac.org.br/index.php/revista 
associados à heterossexualidade, de acordo com o ideário presente na carta citada acima. Não se creditou as mulheres o papel de lutar nas guerras, porém, elas não deixaram de estar presentes neste espaço social de conflito, além de a figura feminina ser constantemente referida nos diários e nas memórias de guerra dos indivíduos que foram convocados a protagonizar este processo.

Nos diários dos mambises a fidelidade de suas esposas era uma preocupação constante, uma necessidade para a garantia da honra e virilidade masculina. Em 21 de abril de 1873 o combatente Francisco Estrada y Céspedes, escreveu para sua esposa:

Séme fiel, amor mío, como hasta aquí lo has sido, que nunca tengas que agachar la frente delante de nadie [...] No digo duda, pero no por la imaginación me ha pasado tal cosa. La mujer que verdaderamente ama a su marido, no puede hacerle traición. Ya que ha venido a tratar sobre este particular, hablando de Elisa Figueredo, de Manzanillo me han dicho que se casó con un hombre casado, con diez hijos y hasta mulato. ¿Qué escándalo! (ESTRADA, 1989, p. 39 apud SIERRA, 2006, p. 62).

Francisco Estrada y Céspedes nos revela que, segundo as representações sociais vigentes em Cuba na segunda metade do século XIX, uma mulher casada devia fidelidade a seu marido e significava um crime moral o envolvimento fora do matrimonio. No entanto, como afirmou o historiador Abel Sierra Madero (2006, p. 65) "Existía una doble moralidad en todos los niveles del mambisado"; apesar da intensa preocupação com a fidelidade de suas esposas, que se encontravam distantes, os chefes, oficiais e soldados mantinham vínculos sexuais com outras mulheres durante a guerra. Legitimada pelos valores de gênero que regiam esta sociedade, a dupla moral sexual outorgou privilégios sociais aos homens em detrimento do exercício da autonomia sexual e da cidadania das mulheres.

Após as guerras de independência e mesmo a partir da constituição da República de Cuba em 1902, a política imperialista do governo norte-americano marcou significativamente a história deste país, inclusive no que tange as relações de gênero. Com a determinação da lei seca (Volstead Act) nos Estados Unidos em 1919, proibindo a venda de bebidas alcoólicas, os empresários que tiveram seus negócios fechados passaram a abrir bares e cabarés na cidade de Havana, capital de Cuba. Através da música e do cinema, o mercado turístico norte-americano ${ }^{8}$ difundiu representações de

8 Os índices referentes ao turismo internacional passaram de 33.000 em 1914 para 200.000 turistas em 1945, e o número de cabarés e casas de prostituição registradas oficialmente foram de 4.000 em 1912 para mais de 13.000 estabelecimentos em 1950 (ÁLVAREZ, 2003, p. 23).

Revista Eletrônica da ANPHLAC, n.14, p. 265-286, jan./jun. 2013. http://revista.anphlac.org.br/index.php/revista 
que este era o país da desinibição sexual, Cuba ficou conhecida internacionalmente como "bordel norte-americano".

A primeira metade do século XX em Cuba foi marcada pela corrupção, instabilidade dos governos, ditaduras e a grande desigualdade social vivenciada pela população (GOTT, 2006). O governo do ditador Fulgencio Batista (1952-1958) foi interpelado pelo assalto ao Quartel Moncada em 26 de julho de 1953 em Santiago de Cuba. Fidel Castro foi uma das lideranças do ataque que foi frustrado pelas forças do exército, mas, após sua condenação e anistia, Fidel estruturou o Movimento 26 de julho e foi para o exílio no México. Retornou a Cuba para combater a ditadura de Batista, refugiando-se na Sierra Maestra em dezembro de 1956. Após anos de guerrilha entre o exército nacional e o exercito rebelde, o segundo grupo venceu o conflito e assumiu o poder em $1^{\circ}$ de janeiro de 1959.

As mulheres cubanas, mesmo ocupando um espaço marginalizado nesta sociedade, não deixaram de atuar no processo revolucionário. Elas transportaram armas, organizaram manifestações, greves e redes clandestinas, além de terem participado do combate armado nos focos da guerrilha no pelotão Mariana Grajales, composto apenas por mulheres.

\section{As representações sociais de gênero em Cuba a partir de 1959}

Com a derrocada da ditadura de Fulgencio Batista em janeiro de 1959, o governo revolucionário assumiu o comando do Estado cubano a partir de uma orientação nacionalista e anti-imperialista. A revolução só foi declarada como socialista em abril de 1961, após a invasão da Praia Girón e a ruptura definitiva de relações com o governo dos Estados Unidos, que financiou a tentativa de golpe. A partir de então, o vínculo político com a União Soviética (URSS) se tornou cada vez mais estreito, refletindo especialmente no direcionamento da concepção política e das ações do Estado cubano (GOTT, 2006).

O novo governo priorizou investimentos nos setores de educação, saúde e emprego, considerados fundamentais para o desenvolvimento social. Tais ações propiciaram transformações significativas, principalmente para a população mais pobre que encontrou nessas políticas a oportunidade para reverter sua condição social. Os primeiros anos da revolução foram momentos de grande efervescência política e 
participação popular, mulheres e homens foram compelidos a construir a nova sociedade socialista, atuando nas "tareas de la revolución".

O exército rebelde transformou-se nas Forças Armadas Rebeldes sob a liderança de Fidel Castro, que assumiu o posto de Comandante-em-Chefe-Militar, cargo de maior autoridade na sociedade revolucionária. O poder bélico/militar esteve ativamente presente neste contexto devido ao perigo eminente de invasão do governo dos Estados Unidos ao território da ilha, pois além da histórica relação de intervenção, a disputa só aumentou com o alinhamento cubano á política soviética, no contexto de polarização da Guerra Fria. Ademais, com o objetivo de apoiar a luta revolucionária em outros países, o governo exportou suas tropas militares ${ }^{9}$.

O Estado reconheceu a existência de desigualdades sociais entre mulheres e homens, a transformação da condição social e a extinção das representações de inferioridade feminina foram questões apresentadas como prioridades no discurso político do governo (CASTRO, 1979). A estratégia política para o alcance da igualdade foi o investimento na inclusão das mulheres no trabalho formal e remunerado. Assim, declarou-se que “(...) una de las metas de la Revolución es igualar económica, política y socialmente a la mujer y al hombre. El proceso mediante el cual se hace patente, es el de la incorporación de la mujer a la población económicamente activa." (COMISIÓN NACIONAL CUBANA DE LA UNESCO, 1962, p. 11).

Antes de 1959 havia inúmeras organizações de mulheres em Cuba ${ }^{10}$. Mas, com a criação da Federación de Mujeres Cubanas (FMC) em 23 de agosto de 1960, as demais organizações de mulheres foram extintas. Nas palavras da sua presidenta Vilma Espín Guillois "11, as "mujeres cubanas, bajo la orientación directa de nuestro gran líder Fidel, tomamos el camino de la unidad, fundiéndonos en una sola organización." (ESPÍN, 1990, p. 6). A FMC surgiu com a finalidade de integrar a mulher à nova sociedade,

\footnotetext{
9 Houve o envio de tropas militares, instrutores de guerrilha, armamentos ou dinheiro para apoiar a luta revolucionária em diferentes países latino-americanos: Argentina, Bolívia e Venezuela; e no continente africano: Congo, Angola, Guiné-Bissau e Congo-Brazzaville. Assim como grupos de estrangeiros viajaram para Cuba para receber treinamento de técnicas de guerrilha, estima-se que cerca de 2 mil latinoamericanos vivenciaram essa experiência durante a década de 1960. Ver: GOTT (2006).

${ }_{10}$ Algumas dessas organizações eram: Unidad Femenina Revolucionaria, Hermandad de Madres, Grupo de Mujeres Humanistas, Brigadas Femeninas Revolucionarias, Columna Agraria e as Secciones Femeninas del 26 de Julio.

11 Vilma Espín Guillois, uma das mulheres que combateu na Sierra Maestra, em 1959 casou-se com Raul Castro, atual presidente da ilha. Presidenta da FMC desde a sua fundação em 1960, Vilma mantevese á frente da organização até a sua morte aos 77 anos, em julho de 2007.
}

Revista Eletrônica da ANPHLAC, n.14, p. 265-286, jan./jun. 2013. http://revista.anphlac.org.br/index.php/revista 
visando o seu aperfeiçoamento social e cultural, constituindo a ponte entre o Estado e as mulheres, atuando junto a outras organizações de massas $^{12}$.

Com o apoio da FMC foi desenvolvida a plataforma de políticas para as mulheres, a partir da inspiração em políticas soviéticas, visando diminuir as atividades domésticas para incluir as mulheres no trabalho formal e remunerado. Foram criados os círculos infantis, os semi-internatos para crianças, as casas geriátricas, restaurantes coletivos nas fábricas e as lavanderias públicas. Além disto, houve medidas para a liberação e gratuidade de métodos contraceptivos e a legalização do aborto.

Corroborando com a perspectiva de constituir novos valores sociais, foi entregue à FMC o Código de Família em 1975. Baseado na moral socialista e com inspirações na legislação vigente na URSS, o Código de Família passou a definir o papel de mulheres e homens no lar ratificando os preceitos defendidos na nova sociedade. No próprio documento estão resumidos os seus principais objetivos:

$\mathrm{Al}$ fortalecimiento de la familia y de los vínculos de cariño, ayuda y respeto recíprocos entre sus integrantes;

Al fortalecimiento del matrimonio legalmente formalizado $\mathrm{o}$ judicialmente reconocido, fundado en la absoluta igualdad de derechos de hombre y mujer;

Al más eficaz cumplimiento por los padres sus obligaciones con respecto a la protección, formación moral y educación de los hijos para que se desarrollen plenamente en todos los aspectos y como dignos ciudadanos de la sociedad socialista;

A la plena realización del principio de la igualdad de todos los hijos. (MINISTERIO DE JUSTICIA, 1977, pp. 284-285).

O Código de Família estabeleceu a igualdade de direitos legais entre mulheres e homens e buscou fortalecer a família, enquanto instituição de formato nuclear, monogâmica e heterossexual. A criação do Código de Família explicita que as ações do Estado socialista não se resumiram ao campo da vida material e objetiva. Os novos valores não foram sistemas isolados da vida cotidiana, eles foram reafirmados nos espaços de trabalho, educação, na imprensa, produção cultural, nas organizações de massa e na nova legislação, ou seja, em diferentes âmbitos da vida social.

O manusear de símbolos através de elementos discursivos e empíricos é fundamental para a construção de representações que legitimem as práticas sociais do

12 Criadas a partir da iniciativa estatal, algumas das organizações de massas são: Comités de Defensa de la Revolución, Asociación de Jóvenes Rebeldes, Asociación Nacional de Agricultores Pequeños, a Unión de Escritores y Artistas de Cuba, Federación de Estudiantes Universitarios. Surgiram outras inúmeras organizações no decorrer dos anos, atualmente são cerca de 170 .

Revista Eletrônica da ANPHLAC, n.14, p. 265-286, jan./jun. 2013. http://revista.anphlac.org.br/index.php/revista 
grupo em exercício no poder (CHARTIER, 1988). Ao debater a categoria de imaginário social, Pesavento (1995) a articula com a categoria de representação social: "O imaginário faz parte de um campo de representação e, como expressão do pensamento, se manifesta por imagens e discursos que pretendem dar uma definição da realidade" (1995, p. 15). Em estudo clássico sobre esta categoria, Baczkó (1985) afirma que ao mesmo tempo em que o imaginário social torna-se local dos conflitos sociais, ele também é objeto de disputas (1985, p.310). E neste sentido, para implementar o projeto socialista a revolução cubana, visou instituir transformações radicais nos diferentes âmbitos da sociedade, e o campo das representações sociais foi um alvo privilegiado de disputas para a construção da "consciência verdadeiramente socialista" (CASTRO, 1979, p. 16).

Ernesto Che Guevara, importante líder da revolução, defendeu intensamente que forjar novos valores sociais era imprescindível para a construção do socialismo. A transformação do modo de produção econômica deveria acontecer simultaneamente à mudança da consciência individual, simbolizada pelo nascimento do "homem novo". Segundo Guevara, estes eram elementos fundamentais para alcançar o comunismo (GUEVARA, 2005, p. 51).

O conceito de homem novo ${ }^{13}$ foi o suporte simbólico-discursivo para constituir a nova cidadania revolucionária (SIERRA, 2006, p. 200). Como fica aparente no discurso de Fidel Castro "A grande tarefa da revolução consiste em formar o Homem Novo", no qual ainda afirmou que essencialmente a tarefa da revolução, consiste em formar "o homem de consciência verdadeiramente revolucionária, o homem de consciência verdadeiramente socialista, o homem de consciência verdadeiramente comunista" (CASTRO, 1978, p. 16). O citado discurso foi proferido em julho de 1968, ano seguinte da morte de Che Guevara em combate na Bolívia, que em sua homenagem foi declarado como o "Ano do Guerrilheiro Heróico".

As representações sobre o homem novo associam-se aos valores de honra, coragem e martírio, que por sua vez, se assemelham as representações sobre os guerrilheiros revolucionários e ao ideário "Patria libre o morir”. O próprio Guevara destacou o significado da atuação e luta de um guerrilheiro, em seu diário na Bolívia,

Este tipo de lucha nos da la oportunidad de convertirnos en revolucionarios, el escalón más alto de la especie humana, pero

13 Em algumas das fontes analisadas encontra-se o termo de "nova mulher", no entanto, este conceito não foi disseminado com a mesma abrangência que o conceito de homem novo.

Revista Eletrônica da ANPHLAC, n.14, p. 265-286, jan./jun. 2013.

http://revista.anphlac.org.br/index.php/revista 
también nos permite graduarnos de hombres; los que no puedan alcanzar ninguno de estos dos estadios deben decirlo y dejar la lucha. (GUEVARA, 1972, p. 186 apud GOOSSES, 2001, p. 212).

Para Guevara a experiência na guerrilha possibilitaria a formação de revolucionários, seres humanos que poderiam ser considerados superiores aos demais, que atingiriam uma posição social destacada enquanto homens. O termo "hombres", utilizado por Guevara não se remete ao sentido de humanidade, supostamente abrangente as mulheres, já que o mesmo defendia que o ideal de guerrilheiro é masculino e a atribuição da responsabilidade do combate armado para as mulheres era justificável somente em situações absolutamente necessárias (GOOSSES, 2001, p. 216). E, ainda segundo a sua perspectiva, os que não tivessem condições de assumir o estágio de revolucionário e a graduação enquanto homens, ou seja, os que não tivessem coragem para morrer como mártires, deveriam deixar a luta.

Conforme a concepção de Guevara, o exercício do poder bélico/militar garantiria ao guerrilheiro um nível de masculinidade hierarquicamente superior ao dos outros homens. Neste sentido, questionamos quais foram às mudanças nas representações dos códigos de masculinidade presentes no perfil do homem inserido no contexto anterior a 1959 e o perfil do guerrilheiro, representado pelo homem novo?

Os homens, aos quais o "homem novo" se contrapunha, eram homens do contexto anterior. Como apontamos, a sociedade cubana foi forjada historicamente através de hierarquias de gênero, classe e raça que estruturavam a ordem social. Contudo, a partir da exaltação de referenciais de virilidade, força e honra, é possível observar semelhanças entre as representações dos códigos de masculinidade dos soldados mambises no século XIX e o ideal do guerrilheiro revolucionário da segunda metade do século XX. Ou seja, mesmo a partir 1959, em que o projeto político socialista visou efetivar transformações sociais de cunho estrutural, as representações de gênero atribuídas ao homem novo e ao guerrilheiro mantiveram resquícios de antigas representações de masculinidade vigentes nesta sociedade.

Além disso, a partir de leituras historicamente construídas sobre a homossexualidade, o governo socialista definiu essa prática como "conducta impropria"14, incompatível com os códigos disciplinares definidos para homens e

14 Conduta imprópria, além de anti-sociais, foram termos cunhados para designar pessoas consideradas perigosas para a sociedade revolucionária por diferentes motivos. Os grupos mais visados foram os

Revista Eletrônica da ANPHLAC, n.14, p. 265-286, jan./jun. 2013. http://revista.anphlac.org.br/index.php/revista 
mulheres. Em 1971, declarou-se nas resoluções finais do primeiro Congresso Nacional de Educação e Cultura de Cuba, que

(...) não se pode permitir que por seus "méritos artísticos", reconhecidos homossexuais influenciem a formação de nossa juventude. Como consequiência, é necessário analisar como se deverá encarar a presença de homossexuais nos diversos organismos da frente cultural. Sugeriu-se o estudo de medidas que permitam o encaminhamento para outros organismos daqueles que, sendo homossexuais, não devam ter participação direta na formação de nossa juventude a partir de atividades artísticas ou culturais. (RESOLUÇÕES, 1980, p. 29).

A partir da compreensão de que a influência de indivíduos com orientação homossexual seria danosa à sociedade, instituiu-se a política de perseguição a este grupo social. Contudo esta prática já era empreendida desde meados da década de 1960. As pessoas consideradas "antisociales", que aos olhos do Estado possuíam "conducta impropria", entre elas os homossexuais, foram enviadas para as Unidades Militares de Ayuda a la Producción (UMAP's), campos de trabalhos forçados que entre 1965 e 1968, aproximadamente, buscaram reeducar os desvios mediante o trabalho político, ideológico e produtivo ${ }^{15}$ (SIERRA, 2006, p. 197).

Portanto, as representações sociais construídas sobre o homem novo definiram a experiência homossexual como uma prática social incompatível com as representações de gênero instituídas para homens e mulheres na sociedade socialista. E especificamente sobre a homossexualidade masculina, apoiando-se em concepções de gênero historicamente forjadas, o Estado compreendeu que a experiência homossexual conflitaria com as exigências de valores de honra, coragem, força física e martírio, símbolos constitutivos das representações do homem novo e do guerrilheiro revolucionário $^{16}$. E, deste modo, foram rearticulados discursos e práticas sociais hostis

considerados contra-revolucionários, homossexuais, hippies ou indivíduos que faziam apologia aos estrangeirismos e alguns grupos religiosos. Ver: ALMENDROS e JIMÉNES-LEAL (1984); SIERRA (2006).

15 Javier Sáez, que foi preso em uma UMAP em 1968, aos quinze anos de idade por ser considerado anti-social, explicita a dicotomia presente na percepção política existente neste período, ao relatar que um homem negro, que havia atuado na campanha de alfabetização em 1961 e que estava na mesma unidade onde ele ficou preso, apanhava cotidianamente dos guardas por permanecer negando que fosse um contrarevolucionário. Segundo Sáez "no le hacían caso, no le creían que fuera revolucionario porque era homosexual y el solo hecho de ser homosexual impedía que fuese aceptado como comunista" (ALMENDROS; JIMÉNEZ-LEAL, 1984, p. 146).

16 Amparo Moreno Sarda (1987, p. 29) destaca que o androcentrismo não pode ser exercido por todos os homens, ou seja, todos os seres humanos do sexo masculino. Os homens que possuem o direito de exercêlo estão situados no centro hegemônico da vida social, o que abarca um campo mais amplo e complexo

Revista Eletrônica da ANPHLAC, n.14, p. 265-286, jan./jun. 2013. http://revista.anphlac.org.br/index.php/revista 
sobre a homossexualidade, utilizando-se do aprisionamento de modo punitivo, reiterando praxes vigentes no período colonial.

A historiadora Tânia Navarro Swain, afirma que “(...) as mudanças na ordem social parecem fazer-se de maneira sempre ambígua: as grades de interpretação do mundo não se transformam de uma só vez e as representações sociais de gênero delas são constitutivas." (SWAIN, 2000, p. 55). Partindo de tal consideração, buscando compreender a manutenção de representações sociais de gênero binárias e dicotômicas, como foi discutido acima, questionamos quais foram às representações sociais atribuídas às mulheres cubanas neste contexto?

A partir da análise das práticas políticas e do discurso da FMC, é possível interpretar quais foram às representações sociais de gênero atribuídas às mulheres cubanas e, conseqüentemente, quais foram às concepções de gênero desta instituição e do Estado socialista.

Durante o II Congresso da FMC, em 1974, foram definidos os cinco objetivos centrais da organização ${ }^{17}$, em um desses, explicitam-se quais foram as funções sociais arrogadas as mulheres:

Elevar cada vez más el nivel ideológico, político y cultural de la mujer, para ponerla en condiciones de jugar el papel que le corresponde como constructora de la nueva sociedad, en sus funciones de trabajadora, madre, formadora de las nuevas generaciones (ESPÍN, 1990, p. 86).

As funções sociais atribuídas às mulheres foram definidas como o trabalho em primeira instância e, em segundo lugar, a maternidade e a formação das novas gerações. De acordo com as estatísticas, $17 \%$ das mulheres desempenhavam trabalho remunerado antes da revolução, depois de 1959 foi estabelecida a meta de incorporar 100 mil mulheres a cada ano na força de trabalho do país, ou seja, o trabalho assalariado constitui-se como uma nova função social para uma parcela significativa das cubanas, que tinham o "deber patriótico de elevar la producción” (ESPÍN, 1990, p. 33). Já, a

das relações de poder a partir da articulação entre diferentes níveis de hegemonia relacionados com o sexo, como a classe, a raça, a idade, a nacionalidade e a orientação sexual.

17 Os cinco objetivos centrais da FMC, definidos no segundo congresso da organização foram: I Enaltecer a mulher, ante si mesma e a sociedade; II - Elevar o nível ideológico, político e cultural da mulher; III - Colocar frente ao Partido e aos órgãos do Estado os problemas materiais, políticos, legais e ideológicos vivenciados pelas mulheres; IV - Direcionar a energia e a força da massa feminina ao desenvolvimento da economia do país; V - Mostrar para as massas femininas dos outros povos que somente com a revolução socialista é possível a transformação radical de uma sociedade, na qual os plenos direitos das mulheres e seus filhos podem ser garantidos (ESPÍN, 1990, pp. 85-86).

Revista Eletrônica da ANPHLAC, n.14, p. 265-286, jan./jun. 2013. http://revista.anphlac.org.br/index.php/revista 
maternidade e a formação das novas gerações, apesar da orientação de novos valores, foram práticas sociais historicamente atribuídas às mulheres como funções naturais.

Ao visar viabilizar as três funções sociais atribuídas às mulheres o Ministério do Trabalho decretou no ano de 1968 as resoluções 47 e 48, após as discussões no XIII Congreso Obrero. A primeira definia a reserva de determinados postos de trabalho, tradicionalmente ocupados por homens, às mulheres. Os postos definidos como preferenciais foram os setores de serviços e esferas administrativas. E a segunda resolução, impedia a atuação em alguns postos de trabalho por serem considerados “nocivas para la función procreadora de la mujer" (ESPÍN, 1990, p. 64). Segundo os Informes do II Congresso da FMC, mais de 25 mil homens cederam seus cargos e passaram a ocupar postos de trabalho que necessitassem de maior esforço físico. $\mathrm{Ou}$ seja, o princípio organizador do trabalho na sociedade socialista foi erigido através da divisão sexual do trabalho, baseada em parâmetros como a preservação da capacidade de procriar e a falta de força física das mulheres.

O ideal de maternidade, como função social, também foi enfatizado no emblema da FMC,

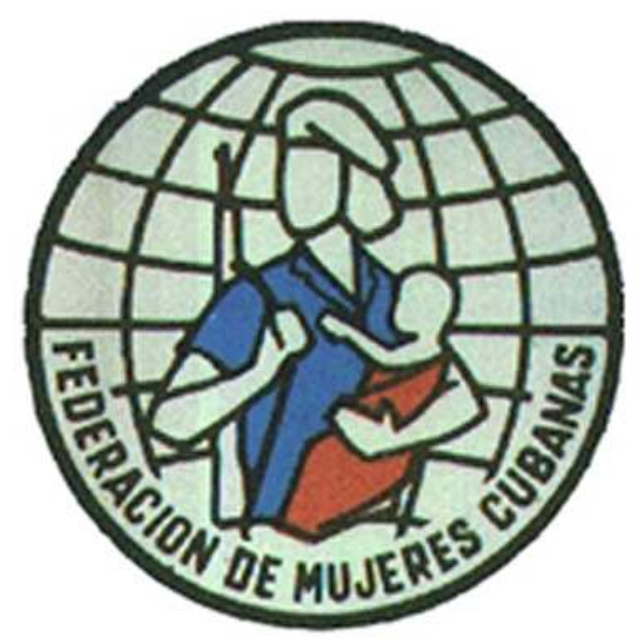

\section{Emblema da Federación de Mujeres Cubanas ${ }^{18}$.}

O símbolo da FMC representa a figura de uma mulher fardada com uma arma nas costas e uma criança nos braços, elas estão vestidas de azul e vermelho, cores da bandeira cubana. Nesta figura estão presentes as representações simbólicas de ideários

\footnotetext{
${ }^{18}$ FEDERACIÓN DE MUJERES CUBANAS. Disponível em: www.mujeres.co.cu/Fmc_archivos/frame. html Acesso em: 21/07/2008.
}

Revista Eletrônica da ANPHLAC, n.14, p. 265-286, jan./jun. 2013.

http://revista.anphlac.org.br/index.php/revista 
como a maternidade, as exigências sociais de militarização e a necessidade de vigilância e defesa da pátria por parte das mulheres. Entretanto, essa imagem está distante do ideal de virilidade guerrilheira atribuída aos homens. E, na prática, nos momentos de conflito, como na invasão da Baía dos Porcos, na crise dos mísseis e na passagem do ciclone Flora, a atuação das mulheres se concentrou no trabalho em hospitais, no recolhimento de roupas, alimentos e medicamentos, nas cozinhas e, principalmente, na substituição dos homens nos postos de trabalho, não no manejo de armas (ESPÍN, 1990, p. 47).

Deste modo, fica evidente a existência da divisão sexual do trabalho também nas atividades de defesa da revolução. Ou seja, foi estabelecido o ideário de "Patria libre o morir" para os homens, contudo, das mulheres cobrou-se a geração de novos filhos, homens, para que estes pudessem manejar armas e, até mesmo, morrer para libertar a pátria como mártires. Negou-se às mulheres o exercício da prática revolucionária guerrilheira, que foi definida por Che Guevara como o caminho para se chegar ao escalão mais alto da espécie humana.

Leituras historicamente construídas sobre as diferenças dos corpos sexuados, que lhes conferem o caráter de "natural", instituíram as representações simbólicas que definiram as funções sociais atribuídas às mulheres na sociedade socialista, aprisionando o corpo feminino à experiência de relações heterossexuais e reprodutivas. Pois, se a legalização do aborto garantiu o direito legal de escolha da interrupção da gestação, a intensa valorização da maternidade, através de diferentes discursos simbólicos, compromete a autonomia feminina na escolha de ter ou não ter filhos.

Tânia Navarro Swain afirma que,

O assujeitamento, a auto-representação das mulheres enquanto matrizes do humano, a imagem de sua inserção social e histórica atrelando corpo, sexo, desejo, identidade em torno da maternidade e heterossexualidade, vem interinar e reproduzir o binário, o sistema sexo/gênero, a inteligibilidade de um mundo desenhado no masculino, distribuidor de tarefas segundo a modelagem e a utilidade dos corpos (SWAIN, 2000, p. 59).

A permanência de concepções de gênero que instituem a divisão sexual do trabalho através de aspectos biológicos garante a estabilidade de representações da divisão social dos espaços privilegiados de poder, a partir da diferença sexual.

Revista Eletrônica da ANPHLAC, n.14, p. 265-286, jan./jun. 2013. http://revista.anphlac.org.br/index.php/revista 
Não obstante, com a democratização da educação as mulheres passaram a constituir um grupo altamente escolarizado ${ }^{19}$. No ano de 1994 elas ocupavam 43,6\% do total da força de trabalho ${ }^{20}$. Mas, apesar de transformações na composição da esfera do trabalho, em 1991 as mulheres ocupavam apenas 28,8\% dos cargos de chefia (ALVAREZ, 1995, p.77). A desigualdade de gênero nos espaços de decisão política é ainda mais explicita ${ }^{21}$.

Porém, ao analisarmos o discurso de representantes da FMC, é possível observar que a ocupação dos espaços de decisão e a autonomia politica das mulheres não foi uma prioridade social, nem mesmo na própria organização.

Al hablar de los logros alcanzados y de la línea de trabajo seguida por la Federación, debemos resaltar que en ellos a sido factor fundamental la acertada dirección de Fidel, conductor excepcional de la Revolución y su Partido, que ha tenido una profunda y real concepción acerca del papel de la mujer en la sociedad, y ha depositado su plena confianza en la masa femenina y en la Federación, situándonos tareas de alta responsabilidad en el proceso, desde los días gloriosos de la Sierra Maestra hasta la etapa actual de construcción del socialismo, trazando siempre las proyecciones adecuadas de nuestro trabajo (ESPÍN, 1990, p. 86).

Com a imputação dos aspectos positivos de seu trabalho à figura de um homem, fica evidente a falta de autonomia da FMC, única organização de mulheres existente em Cuba. Sem problematizar e descontruir as representações historicamente atribuídas a mulheres e homens, mantiveram-se presentes as hierarquias de poder existentes entre os mesmos.

Para Madeline Cámara (2000),

21 No ano de 1992 as mulheres representavam 56,5\% dos graduados no ensino superior, principalmente nos setores da educação e da saúde. Em 1993 as mulheres constituíram 57,7\% dos matriculados nas universidades do país.

20 No setor educativo as mulheres representavam 59\% dos professores, sendo $45 \%$ dos professores de educação superior. No setor da saúde constituíam 35,8\% dos dirigentes, $87 \%$ dos técnicos médios, $62 \%$ dos técnicos de nível superior, 49,3\% dos médicos, e 63\% que compunham o setor da ciência. (FEDERACIÓN DE MUJERES CUBANAS, 1995, p.40).

21 A FMC realizou uma pesquisa no ano de 1988 com cinco mil entrevistados, em igual número de mulheres e homens, na que se buscou compreender a preferência por candidatos do sexo masculino nas eleições do Poder Popular (A partir do ano de 1976 institui-se o Poder Popular, sistema político eleitoral dividido em três segmentos de assembleias municipais, provinciais e nacional. Este sistema foi baseado no modelo soviético). Nesta investigação, $60 \%$ dos entrevistados responderam que não havia distinção serem dirigidos por mulheres ou por homens. Em contrapartida, $40 \%$ dos entrevistados declararam que possuíam preferência pela direção masculina. Quando questionados se consideravam os homens melhores dirigentes, $37,9 \%$ das mulheres e 43,3\% dos homens responderam que sim. Dos 2.110 entrevistados que responderam positivamente a pergunta, 56\% justificaram afirmando que os homens possuíam mais oportunidade e tempo que as mulheres, e $30 \%$ afirmaram que os homens têm mais capacidade por natureza para exercer tais funções (ALVAREZ, 1998, p. 17).

Revista Eletrônica da ANPHLAC, n.14, p. 265-286, jan./jun. 2013. http://revista.anphlac.org.br/index.php/revista 
Si bien bajo el nuevo régimen se subvirtieron los aspectos más peyorativos de la concepción patriarcal: discriminación, violencia sexual, la sociedad cubana dejó intocada la función paternalista y dominante de la figura masculina que pasó a encarnarse en el Estado. Así, en Cuba, como sucedió en Europa Socialista, las mujeres han ganado múltiples derechos, pero entre ellos el más importante es el de servir, cuidar y sacrificarse por el nuevo amo: el estado socialista proletario, con la variante local de estar regido por un carismático caudillo (CÁMARA, 2000, p. 68).

Até mesmo a plataforma de políticas para as mulheres, ações voltadas para a redução das atividades domésticas, visou resolver problemas públicos e de ordem econômica, como o aumento da produção, e não problemáticas vivenciadas pelas mulheres. Pois, não ocorreu a desconstrução da atribuição histórica do trabalho doméstico às mulheres, mas a propagação de que estas funções deveriam ser assumidas pelo Estado, que nunca conseguiu atender à demanda existente. Com a grande crise econômica vigente desde o início da década de 1990, a partir do desaparecimento do bloco socialista, ocorreram drásticos cortes nessas políticas e as mulheres passaram a ser sobrecarregadas em extensas jornadas de serviço ou simplesmente abandonaram os postos de trabalhos formais (BOBES, 1999).

A manutenção de antigas concepções de gênero no contexto de transformações da revolução socialista articulou a convivência de elementos modernos e conservadores, simultaneamente, no mesmo ambiente social. Com a constituição de representações de gênero, pautados em códigos de masculinidade do guerrilheiro e o ideal de maternidade para as mulheres, sustentou-se a ambivalência da dupla moral sexual, como revela o depoimento oral coletado por María Lopez Vigil (1998),

Aquí lo que hay es una doble moral institucionalizada. La doble casa ha sido una institución en este país, y lo ha seguido siendo después de la revolución. La revolución no tocó esas cosas. Aquí, cuando un hombre iba a la guerra en Angola, si el Partido sabía que la mujer que se quedó en Cuba tenía otra pareja, cuando el compañero regresaba, el Partido iba y se lo contaba y le hacían una presión bien fuerte para que se divorciaran. Y si no se divorciaban, él tenía que entregar el carnet de militante. Un héroe del Ministerio del Interior o de las FAR no podía perder su imagen, no podía permitir que su mujer lo hubiera engañado. Pero a nadie en el Partido le preocupaba si el que volvía de Angola había tenido allá no sé cuántas parejas y había dejado un reguero de hijos. Eso no importaba. La mujer tenía que comportarse en Cuba como una vestal, a la espera, con un cinturón de castidad. Y el hombre, total libertad. Suena medieval, ¿verdad?, pero pasó hace unos añitos nada más (LOPEZ, 1998).

Revista Eletrônica da ANPHLAC, n.14, p. 265-286, jan./jun. 2013. http://revista.anphlac.org.br/index.php/revista 
O depoimento acima explicita as contradições entre o discurso oficial e a prática política do Estado cubano. Pois, se o Código de Família estabeleceu a igualdade de direitos absolutos entre homens e mulheres, na prática o Estado atribuiu privilégios sociais aos homens, eleitos como protagonistas do processo revolucionário. A manutenção da dupla moral sexual, que legitimou preocupações com a fidelidade feminina por parte dos soldados mambises no século XIX, foi reinstaurada pelo Partido Comunista que definiu que os códigos de masculinidade dos guerrilheiros revolucionários, homens fortes, viris e honrados que aceitaram morrer em nome da pátria, eram incompatíveis com as representações de homens que poderiam tolerar a traição de suas esposas, mesmo que esses fossem infiéis ${ }^{22}$.

Fundamentada no projeto socialista, a revolução cubana visou construir relações sociais baseadas na justiça e na igualdade, através da transformação radical dos paradigmas em diferentes âmbitos sociais. Ocorreram transformações na esfera política e econômica, mas, a despeito da tentativa de instituir novos valores sociais, no que tange aspectos das relações de gênero, "uma forma primária de dar significado às relações de poder" (SCOTT, 1995, p. 88), as transformações sociais foram limitadas. Pois, mantiveram-se resquícios das de lentes hierarquicamente instituídas, que organizavam as representações simbólicas acerca das funções sociais de mulheres e homens.

\section{Considerações Finais}

Através da análise histórica, buscamos desvelar as construções sobre as representações sociais de gênero no contexto de transformações da sociedade socialista cubana entre 1959 e 1980.

A constituição da sociedade cubana foi fundamentada historicamente através de sistemas de valores assimétricos de classe, raça e gênero. As mulheres foram historicamente marginalizadas dos espaços sociais de poder. A revolução de 1959, que posteriormente assumiu o caráter socialista, foi norteada por um projeto político que ambicionou concretizar transformações radicais nos diferentes âmbitos da vida social.

\footnotetext{
22 Neste sentido, corroboramos com a perspectiva de Quartim (1979), quando este afirma que "Quem quer mudar o mundo não pode fazer do amor sexual o ópio que alimenta paraísos artificiais falaciosos e frágeis. Neste sentido, o 'puritanismo revolucionário' tem sua razão de ser. Mas ele empobrece a revolução e mutila antecipadamente a nova mulher e o novo homem se imagina que a sexualidade socialista será a sexualidade capitalista sem capitalistas" (QUARTIM, 1979, p. 182).
}

Revista Eletrônica da ANPHLAC, n.14, p. 265-286, jan./jun. 2013. http://revista.anphlac.org.br/index.php/revista 
Mulheres e homens foram convocados a erigir a nova sociedade, ambos foram compelidos a assumir posturas de força e abnegação. No entanto, o Estado se apoiou em antigas representações sociais de gênero, baseadas em leituras hierárquicas das diferenças biológicas dos corpos sexuados, instituindo a divisão sexual do trabalho e a divisão sexual das tarefas da revolução.

Foi atribuído aos homens um papel protagonista na construção da sociedade socialista, a função social de guerrilheiro revolucionário foi definida como a máxima representação simbólica da consciência do homem verdadeiramente socialista. No entanto, as representações sociais de gênero atribuídas ao guerrilheiro revolucionário estiveram pautadas em símbolos presentes nas representações de soldados e heróis do passado cubano. Códigos de gênero dicotômicos instituíram a homossexualidade como conduta imprópria à sociedade socialista.

Conferiram-se as funções sociais como trabalhadoras, mães e formadoras das novas gerações às mulheres, contudo, o papel social da maternidade e o cuidado das crianças são funções sociais historicamente atribuídos ao grupo como responsabilidade natural. A ênfase de discursos normativos sobre as relações heterossexuais e reprodutivas, além da instituição de uma dupla moral sexual, comprometeu a autonomia sexual e o exercício pleno da cidadania das mulheres.

Ademais, a figura masculina permaneceu como símbolo representativo do poder instituído, até a única organização de mulheres existente em Cuba imputa os logros de seu trabalho à excepcional direção de um homem. E o próprio conceito de homem novo, evidencia que a construção simbólica da linguagem está pautada na representação do masculino como sinônimo de humanidade, demarcando a existência de noções restritivas para ordenar a identidade subjetiva das mulheres, já que as coloca fora daquilo que é nominável, e particularmente, fora daquilo que foi representado como o símbolo da cidadania socialista.

A revolução de 1959 possibilitou ganhos à população cubana de modo geral, incluindo as mulheres. Porém, através da análise de documentos oficiais, consideramos que as concepções de gênero da FMC e do Estado socialista estiveram pautadas em figuras ambíguas, postuladas a partir de um discurso igualitarista, que visava estar de acordo com o projeto socialista, mas que simultaneamente interagia com discursos baseados em representações de gênero hierárquicas que compreendiam a superioridade masculina; tal perspectiva se encontra enraizada no chão histórico desta sociedade.

Revista Eletrônica da ANPHLAC, n.14, p. 265-286, jan./jun. 2013. http://revista.anphlac.org.br/index.php/revista 


\section{Referências bibliográficas:}

ALMENDROS, Nestor; JIMÉNES-LEAL, Orlando. Conducta Impropia. Madri: Editorial Playor, 1984.

ÁLVAREZ, Inmaculada. El discurso sexual como valor de identidad nacional de lo cubano. Revista de Humanidades, Monterrey, n. 14, 2003, pp. 13-35.

ÁLVAREZ, Mayda. Mujer cubana, problemas de estudio. Revista Temas, La Habana, n. 1, 1995, pp. 77-84.

Mujer y poder en Cuba. Revista Temas, La Habana, n. 14, 1998, pp. 13-25.

BACZKO, Bronislaw. Imaginação social. In: ROMANO, Ruggiero. (org.) Enciclopédia

Einaudi. Lisboa: Imprensa Nacional - Casa da Moeda, v. 5, 1985, pp. 296-332.

BOBES, Velia Cecilia. Participación Vs. Identidad: Mujeres en el espacio público cubano. Perfiles Latinoamericanos, Ciudad de México, n. 15, 1999, pp. 99-118.

CABRERA, Olga; CARRIJO, Orlinda Melo. Brasil e Cuba: Sociedade, história na interseção do gênero, raça e classe social. Revista Brasileira do Caribe, vol. XI, n. 21, jul/dez, 2010, pp.79-102.

CÁMARA, Madeline. Una promesa incumplida: la emancipación de la mujer cubana a finales del siglo XX. In: INSTITUTO MARITAIN DE CUBA. La mujer cubana: historia e infrahistoria. Miami: Universal, 2000.

CASTRO, Fidel Ruz. O homem novo e a nova mulher em Cuba. São Paulo: Global, 1979.

CÉSAR, Maria Auxiliadora. Mulher e Política Social em Cuba: o contraponto socialista ao bem-estar capitalista. Brasília: Alva, 2005.

CHARTIER, Roger. À Beira da Falésia. A História entre Certezas e Inquietude. Porto Alegre: Editora da UFRGS, 2002.

A História Cultural: Entre Práticas e Representações. Lisboa: Difel, 1988.

COMISIÓN NACIONAL CUBANA DE LA UNESCO (Cuba). Cuba y la Conferencia de Educación y Desarrollo Económico y Social, celebrada en Santiago de Chile del 5 al 19 de marzo de 1962. La Habana, 1962.

ESPÍN, Vilma Guillois. Informes centrales de los congresos de la FMC. La Habana, Imprenta Central de las FAR, 1990.

FEDERACIÓN DE MUJERES CUBANAS. VI Congreso de la FMC. Memorias. La Havana, 1995.

Revista Eletrônica da ANPHLAC, n.14, p. 265-286, jan./jun. 2013.

http://revista.anphlac.org.br/index.php/revista 
FEDERACIÓN DE MUJERES CUBANAS. Disponível em: http://www.mujeres.co.cu/Fmc_archivos/frame.html Acesso em: 21/07/2008.

GOOSSES, Andreas. La tierra gira masculinamente, compañero. El ideal de masculinidad del guerrillero. In: HELFRICH, Silke. Género, feminismo y masculinidad en América Latina. El Salvador: Heinrich Boll, 2001, pp. 207-224.

GOTT, Richard. Cuba. Uma nova história. Rio de Janeiro: Jorge Zahar, 2006.

GUEVARA, Che. Socialismo e juventude. São Paulo: Anita Garibaldi, 2005.

LÓPEZ, María Vigil. Cubanas: trazos para un perfil, voces para una historia. Revista Envio, Manágua, n. 200, 1998. Disponível em: <www.envio.org.ni/articulo/398> Acesso em: 15 jun. 2006.

MINISTERIO DE JUSTICIA. La mujer en Cuba socialista. La Habana: Empresa Editorial Orbe, 1977.

MORENO, Amparo Sarda. El arquetipo viril protagonista de la historia. Ejercicios de lecturas no androcéntricas. Cuadernos inacabados. Barcelona: La Sal, 1987.

PESAVENTO, Sandra Jatahy. Em busca de uma outra história: imaginando o imaginário. Revista Brasileira de História, vol. 15, n. 29, São Paulo: ANPUH; Contexto, 1995, pp. 9-27.

POEY, Dionisio Lazáro Baró. Cuba: Estratégias de sobrevivência de mulheres negras (século XX). 210 f. (Tese de Doutorado) Instituto de Ciências Humanas-Departamento de História-Universidade de Brasília, 2009.

QUARTIM, João. O campo socialista e a revolução sexual. In: MANTEGA, Guido (coord). Sexo e poder. São Paulo: Brasiliense, 1979, pp. 167-182.

RESOLUÇÕES do Primeiro Congresso Nacional de Educação e Cultura de Cuba. São Paulo: Livramento, 1980.

SIERRA, Abel Madero. Del otro lado del espejo. La sexualidad en la construcción de la nación cubana. La Habana: Casa de las Américas, 2006.

SCOTT, Joan Wallach. El problema de la invisibilidad. In. ESCANDÓN, Carmen Ramos (org). Género e História. México: Instituto Mora/UAM, 1992, pp. 38-65.

Gênero: Uma Categoria Útil para a Análise Histórica. Educação e Realidade, Porto Alegre, v. 20, n. 2, jul/dez, 1995, pp. 71-99..

SWAIN, Tânia Navarro. A invenção do corpo feminino ou "a hora e vez do nomadismo identitário?". Textos de História, Brasília: UNB, vol. 8, n. 1/2, 2000, pp. 47-84. 
VASSI, Cássia. A família cubana segundo o Código de 1975: novos homens, mulheres e crianças (Trabalho de Conclusão do Curso de História). Faculdade de História, Direito e Serviço Social - Universidade Estadual Paulista/Franca, 2003. . Mulheres em Cuba. Uma perspectiva jurídica (1901-1976). 102f. (Dissertação de Mestrado) Faculdade de História, Direito e Serviço Social - Departamento de História - Universidade Estadual Paulista, Franca, 2006.

Recebido em: agosto de 2012 e aprovado em: outubro de 2012. 